\title{
PSicologia Ambiental e Política AMBIENTAL: QUESTÕES TEÓRICAS E PRÁTICAS
}

\author{
Ricardo Garcia Mira ${ }^{1}$, David Stea ${ }^{2}$ e Silvia Elguea ${ }^{3}$ \\ Universidade de la Coruña, Universidade de South West Texas State, \\ Universidade Autonoma Metropolitana
}

O artigo indaga como contribuir para construir uma ponte entre os psicólogos ambientais e os políticos dado que os psicólogos ambientais estiveram mais preocupados com o desenvolvimento teórico e acadêmico da disciplina do que com conectar áreas aplicadas da Psicologia Ambiental ao mundo complexo da Política Ambiental Aponta que, embora as pontes variem quanto à escala, há outras suposições igualmente importantes a serem consideradas como o contexto democrático e participativo. Apresenta a comunicação uni-direcional versus a bi-direcional e discute o modo como a PA tem visto esta ponte. Finaliza propondo a PA como processo dentro de uma visão alternativa de participação.

Descritores: Política ambiental. Políticos. Psicologia ambiental. Participação política. Comunicação.

1 Professor de Psicologia Social e Ambiental e responsável pela unidade de pesquisa pessoa-ambiente no Laboratório de Pesquisa Social da Universidade de La Coruña (Espanha); membro do Conselho Diretor da IAPS; editor de IAPS Bulletin. Endereço eletrônico: fargmira@udc.es

2 Professor de Geografia e Planejamento na Universidade do Texas (E.U.A.), diretor do Centro de Pesquisa Aplicada Texas-México. Ex-diretor do Centro Internacional para a Cultura e Meio Ambiente (Universidade Autônoma do México). Endereço eletrônico: ds34@txstate.edu

3 Professora do departamento de Humanidades da Universidade Autônoma Metropolitana de Aztapoltaco (México); especialista em Ética Ambiental e Ecofeminismo (Universidade Autônoma do México). Endereço eletrônico: selguea@ hotmail.com 


\section{Psicologia Ambiental e Política Ambiental}

Psicologia Ambiental se refere ao estudo do comportamento humano
relacionado ao ambiente. A Política Ambiental se refere não apenas à própria política, mas às pessoas que fazem política no tocante ao ambiente. Ambas as áreas nem sempre trabalharam juntas tanto quanto desejaríamos. Os psicólogos ambientais estiveram mais preocupados com o desenvolvimento teórico e acadêmico da disciplina do que com conectar áreas aplicadas da Psicologia Ambiental ao mundo complexo dos decisores da Política Ambiental. Do outro lado, as pessoas ligadas à política estão mais acostumadas a estar interessadas em contribuições de pontos de vistas mais técnicos do que os proporcionados pelos psicólogos.

É o momento de refletir, tentando esclarecer alguns pontos. Que tipo de contribuições podem ser retiradas da Psicologia Ambiental que são aplicáveis à Política Ambiental? Como podemos contribuir para a ponte necessária entre psicólogos ambientais e os políticos ${ }^{4}$ ? O ponto ressaltado aqui é que os políticos são pessoas e, assim, parte de nossa análise de comportamento. Isto deveria dar a nós, psicólogos ambientais, algum tipo de vantagem.

Há, pelo menos, dois pontos de referências necessários para se entender a relação do ambiente com esta tarefa, e ambos se referem ao desafio que temos de assumir ao construir a ponte entre a psicologia e a Política Ambiental por meio da participação social, geralmente denominada participação pública. As pontes variam em escala, dependendo da escala do ambiente. Um desses pontos de referência é uma ponte de larga escala, que abarca cidades e grandes concentrações populacionais, onde se requer que o envolvimento se dê pela participação indireta de organizações, ONGs, associações locais, empresas e indústrias e pessoas comuns, tanto quanto de profissionais, incluindo arquitetos, planejadores, psicólogos ambientais e acadêmicos. O outro é uma ponte de escala intermediária ou pequena, que

$4 \mathrm{O}$ autor utiliza o termo policy-makers, significando pessoas que realizam a política, e que passamos a traduzir como políticos, portanto, em um sentido lato de quem se ocupa de políticas públicas. 
abarca bairros e vilarejos, envolvendo a participação direta de indivíduos e organizações. Tanto o setor público quanto o privado têm de dar apoio a essas pontes, porque ambos têm interesses comuns ou complementares.

Além do mais, há duas outras dimensões importantes: a) Pessoas, composta por diferentes atores: Governo, ONGs, Indústrias, Profissionais, e cidadãos; b) outros aspectos de Escala, que dependem do contexto, tanto quanto do meio físico.

\section{Suposições além das considerações quanto à escala}

Há algumas suposições que têm de ser levadas em consideração na discussão que se segue. Em primeiro lugar, supomos que a política é realizada em um contexto democrático (direto ou representativo), e este contexto requer um desenvolvimento anterior de alguma forma de democracia urbana por meio da participação social nos processos de tomada de decisão com respeito ao gerenciamento de recursos. Em segundo lugar, supomos que os políticos em questão têm hoje em dia um interesse genuíno em construir pontes e em investimento público. Finalmente, supomos que o público está aberto a processos inovadores de interação. Os políticos não detêm um monopólio de mentes fechadas.

\section{Comunicação uni-direcional versus bi-direcional}

Tradicionalmente, a comunicação entre os políticos e o público costumava ser uni-direcional. Isto quer dizer que os políticos decidiam muito antes sobre o que fazer em relação ao ambiente, antes de informar o público. O público supostamente deveria receber passivamente as decisões de pessoas que, freqüentemente, nunca elegera diretamente. Atualmente, a consciência ambiental crescente de cidadãos ao redor do mundo promoveu uma considerável demanda por participação na Política Ambiental, e não sempre na direção proposta pelo governo. 
Vamos sugerir um axioma muito básico: A participação é impossível sem uma comunicação bi-direcional. A participação sempre envolve comunicação e a comunicação sempre envolve a participação. Uma é impossível sem a outra.

\section{O que a Psicologia Ambiental nos conta a respeito de como fazer esta ponte entre o público e os políticos em questões ambientais?}

- De modo corriqueiro (para nós, psicólogos ambientais), o ambiente físico faz uma diferença. Ele não é neutro.

- O ambiente físico interage com o ambiente social, cultural e psicológico (Altman, 1973, 1976).

- Além disto, os ambientes influenciam as relações humanas em um sentido amplo, e não apenas o comportamento individual (Sommer). A Psicologia Ambiental transacional (Ittelson, 1970, 1973) precisa considerar isto.

- Em particular, o planejamento ambiental pode: 1) encorajar ou desencorajar as relações e a comunicação, criando espaços sociopetais ou sociofugais (Hall, 1963, 1966; Osmond, 1957); 2) espaços planejados podem encorajar relações hierárquicas e não igualitárias, ou vice-versa.

- Se a participação e a comunicação são completamente entrelaçadas, como postulamos, então um ambiente que desencoraja a comunicação desencorajará a participação.

- Um outro aspecto é a análise de territorialidade e poder. O animal (ou humano) territorial sempre tem a vantagem. O que quer dizer que território físico ou território intelectual = poder. A territorialidade pode ser física ou não-física, e envolve marcadores. Um vocabulário especializado é um modo de marcar um território intelectual, por exemplo. 
- Os espaços que são familiares são parte dos "home range". Eles são mais confortáveis e, portanto, proporcionam mais provavelmente um contexto para uma interação significativa.

- A Psicologia Ambiental vai além do comportamento individual para abranger o comportamento grupal. Um grupo é mais do que uma coleção de indivíduos. Isto se aplica não apenas ao conteúdo do que está sendo relacionado à política pública, mas ao processo de estabelecer aquela relação, relacionando as pessoas e a política.

\section{A Psicologia Ambiental como processo: uma visão alternativa de par- ticipação}

No que se segue, iremos descrever quatro formas de participação, com as suas bases e implicações teóricas e metodológicas:

1. Nenhuma participação. - Esta é a mais comum. Como mencionamos acima, nesta o processo de comunicação é uni-direcional, de cima para baixo, e o público não participa.

2. Participação simbólica ou "token”. Esta é a seguinte mais œmum (por exemplo, uma reunião na comunidade); geralmente, uma reunião comunitária, em um evento que acontece em um "espaço público", que é realmente um território do governo ou de um grupo diferente daquele do público em geral. De uma perspectiva do público, é um território alheio (não "casa", não parte dos "limites da casa"). É, muito provavelmente, um espaço hierárquico. $\mathrm{O}$ Governo ou os políticos estão em uma posição superior, retendo o poder e o controle. Eles estão freqüientemente em uma posição superior, sobre uma plataforma. As pessoas são apenas a audiência, receptadores de informação, e freqüentemente sentados abaixo. A participação do público está usualmente restrita a colocar perguntas. 
3. Participação ou comunicação distorcida. Um exemplo desta é o mal-uso de questionários, especialmente aqueles com questões fechadas, usando questões de múltipla escolha ou escalas Likert. Um questionário pode não conseguir obter a informação que seja importante. Ele não cobre todos os pontos que o sujeito poderia expressar. A pessoa que planeja o questionário pode apenas colocar questões sobre o que ela já conhece. Em outras palavras, se você não sabe que um item, um fenômeno ou um problema existe, você não pode perguntar sobre ele. Conseqüentemente, os questionários são maneiras pobres de eliciar informações inteiramente novas. Além disto, forçam tudo a estar em uma forma verbal, que é boa apenas quando se estiver falando sobre uma informação inerentemente verbal. Pode não ser boa para a informação espacial, ou a informação que foi recebida em uma forma gráfica. A enunciação teórica importante é: se entendermos a informação como algo a ser comunicado, então, a forma específica de comunicação se torna relevante.

Consideremos a teoria da comunicação, conforme expressa por Shannon e Weaver (1949). O canal de comunicação entre a fonte e o receptador pode ser afetado por aquilo que chamamos de ruído. Ruído aqui se refere a: a) literalmente barulho; diferença cultural; diferenças sócio-econômicas; lacuna profissional; formas específicas de comunicação (verbal, gráfica, manipuladora, etc.). O ruído, como usado aqui, significa degradação da comunicação. Quando há uma mudança de uma forma de comunicação para outra, há degradação da mensagem. Assim, se uma informação é dada em forma gráfica (por exemplo, por um arquiteto) e precisa ser mudada para uma forma verbal (por exemplo, por um questionário), há frequientemente distorção. Isto é o que ocorre, freqüentemente, na comunicação "arquitetural". Por exemplo, se um arquiteto apresenta desenhos, e o público precisa responder em palavras (o que, por sua vez, deve ser interpretado pelo arquiteto na forma de outros desenhos), o desentendimento muitas vezes ocorre. 
Nestes casos, o que parece ser participação, pode produzir resultados piores do que nenhuma comunicação.

\section{Participação efetiva}

a) Um dos aspectos mais importantes para tornar possível a participação efetiva é o contexto ambiental. Os indivíduos têm de se sentir em casa, em um contexto não ameaçador, que minimiza diferenças de status. Relativo a isto, há a teoria do cenário de comportamento (behavior setting): proporcionar cenários de comportamento adequados (Barker, 1968; Schogen, 1989) que permitem, e de fato coagem, o comportamento apropriado aos cenários físicos e culturais. Um cenário que encoraja a participação é, de preferência, um complexo comportamento-ambiente que envolve algo que a comunidade realiza regularmente, como um jantar comunitário uma vez por mês, por exemplo. Tal cenário deveria respeitar e usar as apresentações e as finalizações cerimoniais normais, com normas funcionais para as reuniões e para se alcançar um acordo (por exemplo, assinar, votar). Observar normas periféricas (por exemplo, comer, música...) e, em geral, o que quer que seja que as pessoas normalmente fazem, é apropriado.

b) Se possível, todos os grupos de idade e gênero devem ser incluídos, encorajando a participação de todos, mas respeitando normas culturais (isto é, proporcionado a oportunidade para participar mas não de modo que viole tabus).

c) As pessoas acham que os problemas ambientais são confusos. $\mathrm{Na}$ primeira sessão de participação, tente fazer com que a comunidade selecione um problema (um problema específico): este deve ser um problema sobre o qual todos concordam, e que pode ser facilmente resolvido, para dar à comunidade a experiência de ter sucesso (de outro modo, a participação pode diminuir nas sessões futuras). 
d) Em problemas mais difíceis, as pessoas devem ter os mesmos instrumentos de comunicação que os profissionais (por exemplo, instrumentos gráficos simples, tais como modelos ambientais que podem ser manipulados). Isto proporciona uma importante oportunidade para uma aprendizagem mútua. Os profissionais aprendem sobre o contexto local vendo os problemas ambientais, enquanto o público aprende as formas de representação usadas pelos profissionais. Esta é uma forma de educação ambiental que é, de fato, educação sobre formas de representação ambiental.

e) Encoraje o trabalho em grupos. Cinco pessoas é, freqüentemente, um bom tamanho de grupo. Para isto, cenários sociopetais são essenciais. A forma da mesa pode ser importante, como detalhado posteriormente.

f) Encoraje "decisões revogáveis". As pessoas (especialmente as super-educadas, tais como muitas aqui presentes) detestam tomar decisões permanentes, de modo que acabam por se comprometer em uma "paralisia da análise", em "falar de um problema até a morte", sem alcançar qualquer solução. A paralisia da análise permite aos políticos ignorar a participação, vista como produzindo resultados não úteis. As pessoas deveriam ser informadas que está tudo bem em se mudar uma decisão temporária. Tais "decisões temporárias" forçam o participante a dar voz às suas razões para aquela decisão, o que tornará explícitos valores implícitos.

g) Outra razão para proporcionar um cenário confortável é que novas idéias emergem melhor quando as pessoas se divertem. O processo pode ser divertido. Deveria ser. Fazer a participação se parecer com trabalho pesado pode reduzir a futura participação.

h) Considere a "psicologia micro-ambiental" como referência para fazer cenários interativos. Para grupos trabalhando ao redor de mesas, mesas redondas ou quadradas são boas. Mesas compridas ou com diferença vertical, assim como colocar umas mesas no palco e outras abaixo, não são. É necessário minimizar a possibili- 
dade de que "ditadores" de grupo surjam por acidente (devido à ação ambiental não planejada, tal como uma forma errada de mesa ou a sua colocação).

i) Depois de um certo tempo, cada grupo é encorajado a escolher um "representante" (vocera) que contará aos outros grupos sobre as conclusões de seu grupo e as razões para aquelas decisões, usando o material gráfico que o grupo reuniu.

j) O planejamento do espaço de trabalho deve ser tal que este processo possa acontecer sem criar uma hierarquia dentro ou entre os grupos.

k) Isto é seguido por uma questão "aberta" e um período de comentários. Cada grupo pode comentar sobre todos os demais grupos.

1) Há necessidade de ter uma cerimônia de encerramento adequada, com expressão de consideração por todos.

m) De modo ideal, este processo deve ser interativo, e repetido em várias ocasiões (quando o maior número de pessoas são livres para participar). No melhor dos casos, pode haver um valioso benefício secundário: um processo efetivo agradável de comunicação pode servir para intensificar as relações dentro da comunidade.

Garcia-Mira, R., Stea, D., \& Elguea, S. (2005). Environmental psychology and environmental policy: Theoretical and practical questions. Psicologia USP, 16(1/2), 249-259.

Abstract: The article asks how one can contribute to build a bridge
between environmental psychologists and politicians, since environmental
psychologists have been more concerned about the theoretical and
academic development of the discipline than about connecting applied areas
of Environmental Psychology with the complex world of Environmental
Policy. It argues that, although the bridges vary in scale, there are other
equally important suppositions to be considered, such as the democratic and
participative context. It presents uni-directional x bi-directional
communication and discusses the way in which Environmental Psychology 
has seen this bridge. It concludes proposing Environmental Psychology as a process within an alternative view of participation.

Index terms: Environmental policy. Politicians. Environmental psychology. Political participation. Communication.

Garcia-Mira, R., Stea, D., \& Elguea, S. (2005). Psychologie de l'environnement et politique de l'environnement: questions theoriques et pratiques. Psicologia USP, 16(1/2), 249-259.

Résumé: L'article s'enquiert de la façon suivant laquelle il serait possible de contribuer à construire un pont entre les psychologues environnementaux et les politiciens, vu que les psychologues environnementaux se sont davantage souciés du développement théorique et académique de la discipline que de la façon dont on relierait des domaines appliqués de la Psychologie de l'Environnement au monde complexe de la Politique de l'Environnement. Il relève que, bien que les ponts varient quant à l'échelle, il y a d'autres suppositions également importantes à considérer, telles que le contexte démocratique et participatif. Il présente la communication unidirectionnelle versus la bidirectionnelle, et discute de la façon dont la Psychologie de l'Environnement a envisagé ce pont. Il termine en proposant la Psychologie de l'Environnement comme processus dans une vision alternative de participation.

Mots-clés: Politique environnementale. Politiciens. Psychologie de l'environnement. Participacion politique. Communication.

\section{Referências}

Altman, I. (1973). Some perspectives on the study of man-environment phenomena. Representative Research in Social Psychology, 4, 109-126.

Altman, I. (1976). Environmental psychology and social psychology. Personality and Social Psychology Bulletin, 2, 96-113.

Barker, R. G. (1968). Ecological psychology. Stanford, CA: Stanford University Press. 
Hall, E. T. (1963). A system for the notation of proxemic behavior. American Anthropologist, 65, 1003-1027.

Hall, E. T. (1966). The hidden dimension. Garden City, NY: Anchor / Doubleday.

Ittelson, W. H. (1970). Perception of the large-scale environment. Transactions of the New York Academy of Sciences (Series II), 32, 807-815.

Ittelson, W. H. (1973). Environment perception and contemporary perceptual theory. In W. H. Ittelson (Ed.), Environment and cognition. New York: Seminar Press.

Osmond, H. (1957). Function as the basis of psychiatric ward design. Mental Hospitals, 8, 23-30.

Schoggen, P. (1989). Behavior settings. Stanford, CA: Stanford University Press.

Shannon, C. E., \& Weaver, W. (1949). The mathematical theory of communication. Urbana, Il: University of Illinois Press.

Sommer, R. (1969). Personal space. Englewood Cliffs, NJ: Prentice Hall.

Sommer, R. (1980). Environmental psychology. A blue-print for the future. APA Monitor, 11, 2.

Recebido em 5.04.2004

Revisto e encaminhado em 23.02.2005

Aceito em: 7.03.2005 